\title{
EXPERIMENTAL INVESTIGATION OF WATER COOLER SYSTEM BY USING ECO-FRIENDLY REFRIGERANT (R-134a)
}

\author{
Rajendra B. Velkar ${ }^{1 *}$, Nagesh S. More ${ }^{2}$, Vaibhav K. Dongare ${ }^{3}$, Anirudha G. Mulgund ${ }^{4}$, Vaibhav V. Gardi ${ }^{5}$, \\ Dattatray D. Surve ${ }^{6}$, \\ *1,2,3,4,5,6 Department of Mechanical Engineering, RMCET, University of Mumbai, India, \\ *1rajuvelkar@gmail.com; ${ }^{2}$ nageshmore43@gmail.com; ${ }^{3}$ vaibhavdongare@gmail.com; ${ }^{4}$ anirudhahi5@gmail.com; \\ 5vaibhavvgardi3995@gmail.com; ${ }^{6}$ surve.datta19@gmail.com;
}

\section{*Corresponding Author: -}

rajuvelkar@gmail.com

\begin{abstract}
: -
With the recent government regulations, of banning the ozone depleting substances and Kyoto protocol later on curtaining to the use of substances which contribute to global warming, conventional refrigerants are to be replaced by the environment friendly refrigerants. Present day mankind depends heavily on refrigeration for his daily needs. This can be noticed by wide range of applications such as for home refrigeration, comfort cooling, preservation and transport, commercial and industrial air conditioning, hospitals, offices etc. These refrigeration system works on simple vapour compression refrigeration cycle. The water cooler system also works on simple vapour compression refrigeration cycle and uses R134a as a refrigerant. It is environment friendly. The performance of refrigerant R134a has been found and the results were used to evaluate the behavior of the system under varying load conditions and to measure the COP of the system. The water cooler system has been designed and fabricated specially for small capacity.
\end{abstract}

Keywords: - Kyoto Protocol, Vapour compression refrigeration system, refrigerant, ozone depletion, global warming, COP 


\section{INTRODUCTION}

The term refrigeration is defined as the process of removal of heat from a substance under controlled conditions. It also includes the process of reducing and maintaining and the temperature of the body below the general temperature of its surrounding. In other words, the refrigeration means a continuous extraction of heat from a body whose temperature is already below the temperature of its surrounding. [5]

Water cooler system is a cooling equipment consisting of a thermally insulated compartment and a refrigeration system which works vapour compression refrigeration cycle (VCRS). The first VCRS system was developed in 1834 by Jacob Perkins using hand operations. In refrigeration process, the working fluid holding down a job as the heat absorber or cooling agent is called as refrigerant. The refrigerant used does not leave the system throughout the system alternately condensing and evaporating. The vapour compression refrigeration system is now-a-days used for all purpose refrigeration. It is generally used for all industrial purposes from a small domestic refrigerator to a big air conditioning plant. [3]

The purpose of carrying out the research work is to observe the performance of fabricated test rig according to the changing parameter i.e. time. Parameters considered for comparing the performance involves coefficient of performance (COP), refrigerating effect, compressor work and compressor discharge temperature. In addition to this, the effect of different evaporator and condenser temperature on above mentioned performance parameters is also reported for the refrigerant R-134a.

\section{Working Of Vapor Compression Refrigeration System}

The process of refrigeration occurs in a system which encompasses of a compressor, a condenser, expansion device and an evaporator. VCRS system functions based on reversed Bryton cycle. The VCRS system consists of four main components which are compressor, condenser, expansion device and evaporator. Fig. 1.0 shows the schematic diagram of the VCRS system. Compressor is used to compress the low temperature and pressure refrigerant from the evaporator to high temperature and pressure. After compression the high temperature and pressure refrigerant is discharged into the condenser though the delivery or discharge valve B.

The Condenser consists of coils of pipe in which the high temperature and pressure refrigerant is cooled and condensed. The refrigerant, which passing through the condenser, gives up its latent heat to the surrounding condensing medium which is normally air or water. The condensed liquid refrigerant from the condenser is stored in the vessel known as receiver from where it is supplied to evaporator through the expansion valve (i.e. capillary) or refrigerant control valve. The function of the expansion valve is to allow the liquid refrigerant under high temperature and pressure to pass at a controlled rate after reducing its temperature and pressure. Some of the liquid refrigerant evaporates as it passes though the expansion valve, but the greater portion is vaporized in the evaporator at low temperature and pressure.

Next it travels to the evaporator. An Evaporator consists of coils of pipes in which the liquid-vapour refrigerant at low temperature and pressure is evaporated and changed into vapour refrigerant at low pressure and temperature. In evaporating, the liquid vapour refrigerant absorbs its latent heat of vaporization from the medium (water) which is to be cooled. The performance of the water cooler system is to be evaluated by using experimental methods which is carried out by using the specially developed test rig. The test rig can be modified and upgraded if required. The work explains some of the technical modification and evaluation of the refrigeration system under varying load condition. The refrigeration system used to test the concept has a low pressure with single hermetically sealed compressor. [5]

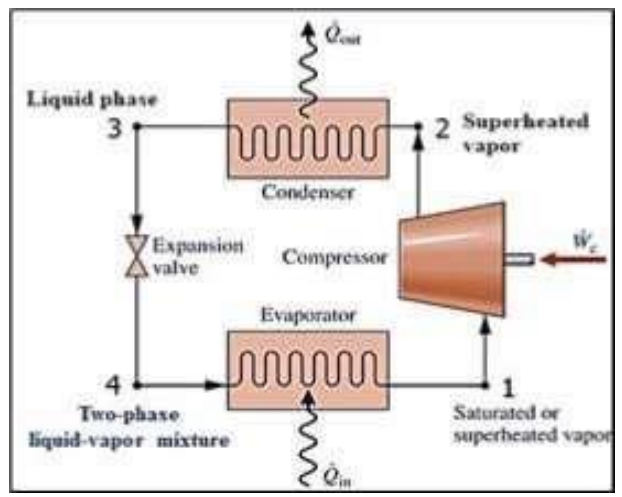

Fig. 1 Schematic diagram of Vapor Compression Refrigeration Cycle.

\section{Design And Fabrication Of Test Rig System}

The overall physical dimensions $(80 \times 30 \times 85) \mathrm{cm}$ and $30 \mathrm{~kg}$ weight. Fig 2 shows the diagram of the test rig used in the experiment. The unit is having three phase electricity reciprocating compressor. The condenser and evaporator coils are made of copper. The test rig accommodates a motor fan to run the condenser.

Selection of refrigerant: $\mathrm{R}-134 \mathrm{a}\left(\mathrm{CF}_{3} \mathrm{CH}_{2} \mathrm{~F}\right.$ - Tetrafluoro Ethane) which is an ethane based refrigerant was selected to be tested for the test-rig. This refrigerant is commercially available. It is considered to be the most preferred substitute for $\mathrm{R}-12$. Its boiling point is $-26.5^{\circ} \mathrm{C}$. R-134a has no chlorine atom, therefore it has zero ozone depleting potential (ODP) and less global warming potential (GWP) as compared to R12. [5]

Refrigerant Charging: The refrigerant may be charged in liquid or vapour phase. This depend upon various factors such as amount of refrigerant, time of charging, ambient temperature of the surrounding. Charging of refrigerant is one of the 
most critical task. Amount of refrigerant to be charged is so selected that it maintains desired suction and discharge pressure. A better alternative method is to charge the refrigerant by weight. Sometimes charging is done without the aid of any equipment's, this system uses suction pressure and discharge pressure as indicative of the charge quantity. However, this needs a high level of skill and human experience.

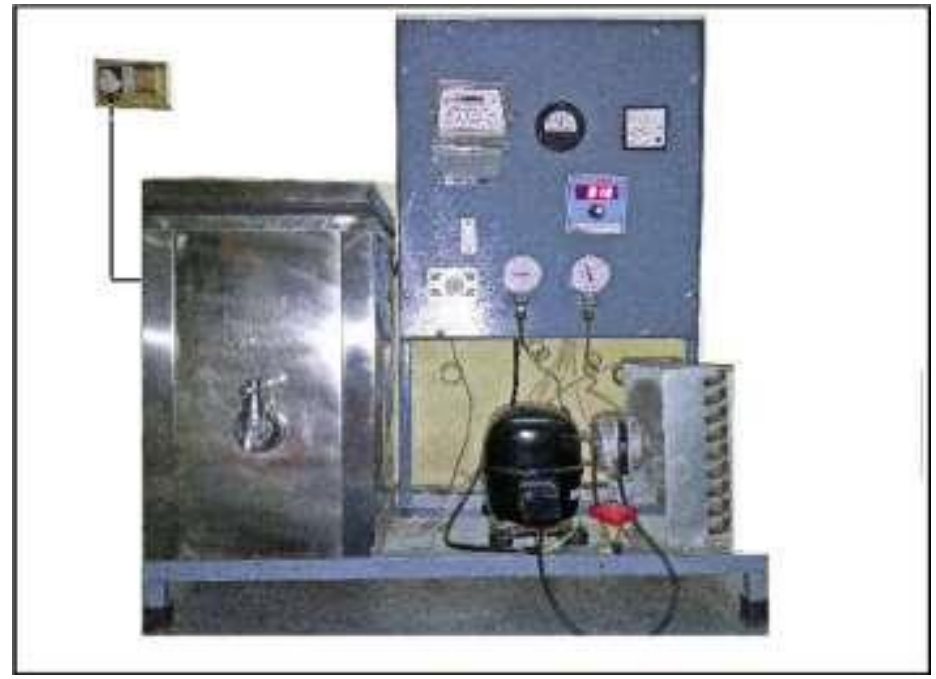

Fig. 2 Experimental Setup.

\begin{tabular}{|c|c|c|}
\hline TITLE & PARAMETER & DESCRIPTION \\
\hline Refrigeration System & Cooling Capacity & $0.030 \mathrm{TR}$ \\
\hline Compressor & & $\begin{array}{c}\text { Reciprocating \& } \\
\text { hermetically sealed. } \\
94 \text { watt } \\
250 \text { PSI } \\
15-20 \text { PSI } \\
0.8 \mathrm{~A}\end{array}$ \\
\hline Condenser & $\begin{array}{l}\text { No. of rows- } \\
\text { L X B X H }\end{array}$ & $\begin{array}{c}\text { Forced convection air } \\
\text { cooled. } \\
9 \times 9 X 2 \text { (inch) } \\
{[1 \text { inch }=12 \text { rows of fins }]}\end{array}$ \\
\hline Condenser fan & $\begin{array}{c}\text { Type of flow } \\
\text { Fan motor rating }\end{array}$ & $\begin{array}{l}\text { Axial flow. } \\
5 \text { watt }\end{array}$ \\
\hline Evaporator & & $\begin{array}{c}\text { Water cooler for } 10 \\
\text { liters capacity made of } \\
\text { stainless steel } \\
\text { Outer } \\
\text { body }=12 * 12 * 12(\text { inch }) \\
\text { Inner } \\
\text { body }=8 * 8 * 10 \text { (inch) }\end{array}$ \\
\hline Expansion device & $\begin{array}{c}\text { Device } \\
\text { Diameter- }\end{array}$ & $\begin{array}{l}\text { Capillary Tube. } \\
0.031 \text { inch }\end{array}$ \\
\hline Insulation & & Puff insulation \\
\hline Refrigerant & & $\begin{array}{l}\text { R134a (Tetrafluoro } \\
\text { ethane) }\left(\mathrm{CH}_{3} \mathrm{CH}_{2} \mathrm{~F}\right) \text {. }\end{array}$ \\
\hline
\end{tabular}

Table 1. Specification of the test rig.

\section{Test Procedure}

At the beginning of test, the system was kept running for at least 15 minutes. This was done to ensure that all the temperature and pressure gauges are working for the circulated refrigerant. After the initial set up the various temperature and pressure were recorded for no load conditions. After this, the observations were taken at an interval of 5 minutes each for full load condition i.e. the evaporator was completely filled with water. After 1 hour readings were taken at constant rated current condition of $0.8 \mathrm{~A}$. The readings were taken at ambient atmospheric conditions i.e. $27^{\circ} \mathrm{C}$ and 1 atm pressure. The test was usually conducted at high speed of condenser fan at about $1440 \mathrm{rpm}$. 


\section{Analysis Of Experimental Data}

The main purpose of carrying out the research work is to observe the performance of fabricated test rig according to the changing parameter i.e. time. The test was carried out on the water cooler test rig for the refrigerant R-134a. The performance measure such as coefficient of performance (COP), refrigerating effect, and compressor work and compressor discharge temperature are considered for the analysis. The results of the tests conducted are plotted and shown below:

Observations after 1 hour when evaporator is full of water:

\begin{tabular}{|c|c|c|c|c|c|c|c|c|c|c|}
\hline $\begin{array}{c}\text { OBS. } \\
\text { NO. }\end{array}$ & $\mathrm{P}_{1}$ & $\mathrm{P}_{2}$ & $\mathrm{~T}_{1}$ & $\mathrm{~T}_{2}$ & $\mathrm{~T}_{3}$ & $\mathrm{~T}_{4}$ & $\mathrm{~T}_{5}$ & $\mathrm{~V}$ & $\mathrm{I}$ & $\mathrm{COP}$ \\
\hline 1 & 17 & 132 & 6 & 50 & 22 & -1 & 10 & 230 & 0.8 & 7 \\
\hline
\end{tabular}

Where,

$\mathrm{P}_{1}=$ Evaporator Pressure

$\mathrm{P}_{2}=$ Condenser Pressure

$\mathrm{T}_{1}=$ Evaporator Outlet temperature

$\mathrm{T}_{2}=$ Condenser Inlet Temperature

T3 $=$ Condenser Outlet Temperature

T4 = Evaporator Inlet Temperature

$\mathrm{T} 5=$ Water Temperature in Evaporator

$\mathrm{V}=$ Voltage Reading

$\mathrm{I}=$ Current Reading

Sample calculation for first observation taken after 1 hour when evaporator is completely filled with water (full load condition):

From P-h chart,

$\mathrm{h}_{1}=$ Enthalpy at Evaporator Outlet Temperature (i.e. at $\left.6^{\circ} \mathrm{C}\right)=408.33 \mathrm{KJ} / \mathrm{Kg}$

$\mathrm{h}_{2}=$ Enthalpy at Condenser Inlet Temperature (i.e. at $\left.50^{\circ} \mathrm{C}\right)=433.33 \mathrm{KJ} / \mathrm{Kg}$

$\mathrm{hf}_{3}=\mathrm{h}_{4}=$ Enthalpy at Condenser Outlet Temperature (i.e. at $\left.22^{\circ} \mathrm{C}\right)=233.33 \mathrm{KJ} / \mathrm{Kg}$

$$
\mathrm{COP}=\frac{h 1-h 4}{h 2-h 1}=\frac{h 1-h f 3}{h 2-h 1}=\frac{408.33-233.33}{433.33-408.33}=7
$$

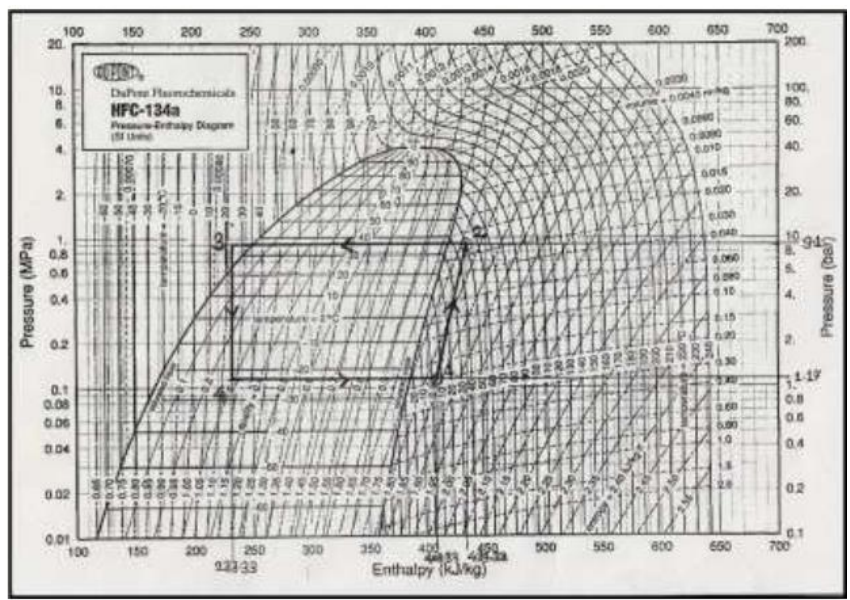

Fig. 3 Pressure- Enthalpy (P-h) Diagram for R-134a

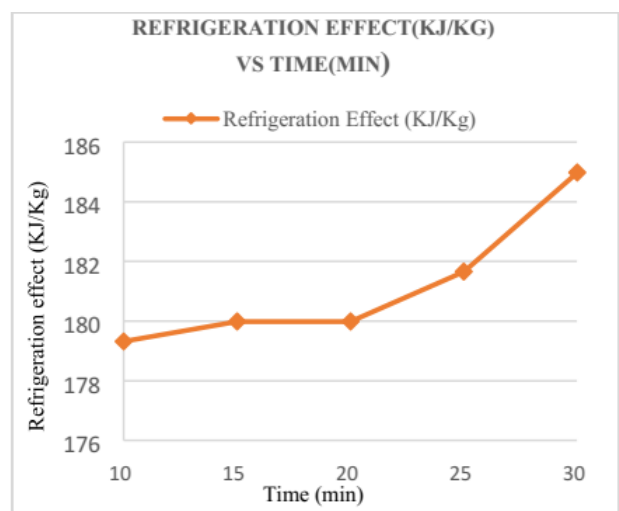

Fig.4 Refrigeration effect vs Time 


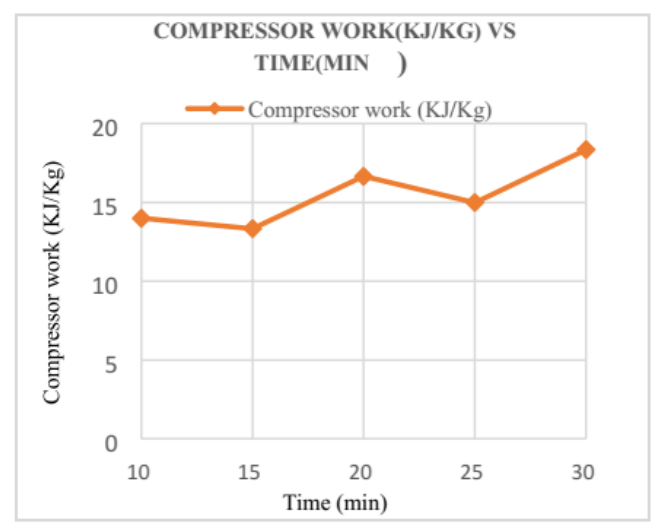

Fig.5 Compressor Work vs Tim

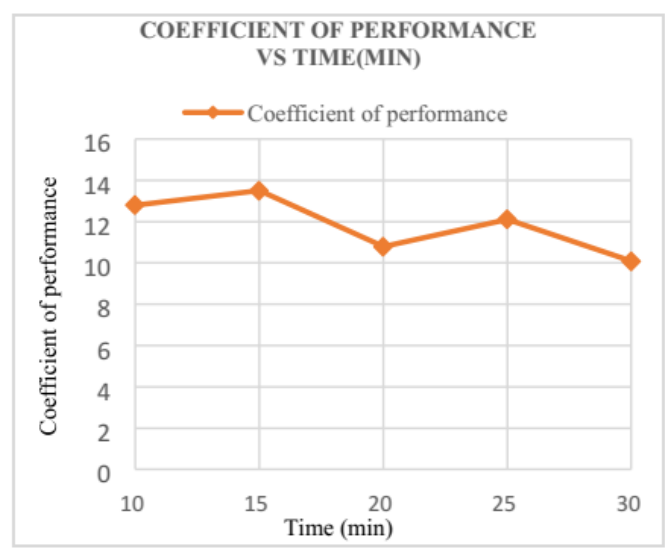

Fig.6 Coefficient of Performance vs Time

Fig. 4, 5 and 6 shows variation in refrigeration effect, compressor work and coefficient of performance with respect to time for refrigerant R-134a. As time increase refrigeration effect increases and Coefficient of Performance (COP) decreases. The Compressor work fluctuates as time increases, and after 1 hour when the system gets stabilized the COP of the water cooler test rig remains constant. The value of COP achieved with refrigerant R134a is 7 at chilled water evaporator temperature $10^{\circ} \mathrm{C}$.

\section{Conclusion}

The objective of carrying out the research work is to observe the coefficient of performance of R-134a. The refrigerant is a heat carrying medium which during their cycle (VCRS cycle) in the refrigeration system absorbs heat from a low temperature system and discards the heat to a higher temperature system. In the present days, many new refrigerants including halo-carbon compounds, hydrocarbon compounds are used for refrigeration applications. R134a is considered to be the most preferred substitute for other refrigerants, since the refrigerant R-134a has less global warming potential and zero ozone depletion potential. Hence, various observations and results obtained from the experimental investigations shows that, R-134a is a better substitute for other refrigerants on the basis of COP. Meanwhile, the quest for better refrigerants continues. Seeing new refrigerants, natural refrigerants appears to be the best choice in the long run.

\section{References}

[1].M. Ashok Chakravarty \& M.L.S Deva Kumar, "Experimental investigation of alternate refrigerant for R-22 in window air conditioning system".

[2].Mukesh K Agrawal \& Dr Ashok G. Matane, "Evalution vapour compression refrigeration system using different refrigerants".

[3].G. Venkatarathnam \& S Shrinivasa Murthy, "Refrigerants for vapour compression refrigeration system".

[4].J.K. Dabas, A.K Dodeja, Sudhirkumar, K.S Kasana, "Performance characteristics of vapour compression refrigeration system under real transient condition"

[5].R.S Khurmi and J.K. Gupta, A textbook of Refrigeration \& Air Conditioning, 2nd Edition, 2012.

[6].Arora \& Domkudwar, A course in Refrigeration \& Air Conditioning, 7th Edition, Delhi, Dhanpat Rai \& Co, 2012 